\title{
Long-term no-take marine reserve and benthic habitat effects on coral reef fishes
}

\author{
Garry R. Russ ${ }^{1,2, *, * *}$ Kelsey I. Miller ${ }^{1, * *}$, Justin R. Rizzari ${ }^{1,2}$, Angel C. Alcala ${ }^{3}$ \\ ${ }^{1}$ College of Marine and Environmental Sciences, James Cook University, Townsville, Queensland 4811, Australia \\ ${ }^{2}$ Australian Research Council Centre of Excellence for Coral Reef Studies, James Cook University, Townsville, \\ Queensland 4811, Australia
}

${ }^{3}$ Angelo King Center for Research and Environmental Management, Silliman University, Dumaguete City, 6200, Philippines

\begin{abstract}
No-take marine reserves (NTMRs) are advocated as tools to enhance or maintain density and assemblage structure of coral reef fishes. These reef fish population and assemblage attributes may be affected by both NTMR protection and benthic habitat change. Before-aftercontrol-impact-pair (BACIP) sampling designs and long-term (8-30 yr) monitoring at 4 Philippine NTMRs were used to examine the relative effects of NTMR protection and benthic habitat change on densities and assemblage structures of fishery-targeted (Lethrinidae and Lutjanidae) and nontargeted (Pomacentridae) reef fishes. Targeted fish density increased significantly in NTMRs relative to fished control sites at all reserves over time. Non-targeted fish density and hard coral cover displayed a variety of patterns of change over time (unrelated to NTMR protection), but closely mirrored each other. Targeted fish were considered potential predators of non-targeted fish. Availability of potential prey for predators had a larger influence than the effect of potential predators on prey, with both processes much weaker than effects of habitat change. Multivariate analyses of long-term temporal data indicated that $65.8 \%$ of the variance in assemblage structure of non-targeted pomacentrids was explained by benthic habitat variables (structural complexity, cover of dead substrate) whereas NTMR protection alone explained only $9.7 \%$. In contrast, $36.2 \%$ of assemblage structure of targeted lethrinids/lutjanids was explained by duration of NTMR protection ( $42.2 \%$ excluding effects of typhoons at one reserve), with habitat variables alone explaining $24.7 \%$. These results help clarify the relative effects of NTMR protection, benthic habitat change, and potential trophic interactions on reef fishes targeted and non-targeted by fishing.
\end{abstract}

KEY WORDS: No-take marine reserves - Benthic habitat effects - Target and non-target fishes · Fishing $\cdot$ Fish assemblage structure $\cdot$ Predation $\cdot$ Philippines $\cdot$ Coral reef fishes

\section{INTRODUCTION}

Globally, declining fish stocks and anthropogenic threats to marine environments are raising concerns about the state of marine ecosystems. Unsustainable fisheries have resulted in reduced size of fishery stocks and degraded marine habitats (Jackson et al. 2001, Myers \& Worm 2003). New fishery management strategies, such as ecosystem-based management (Pikitch et al. 2012), that examine total impacts to marine ecosystems are required. No-take marine reserves (NTMRs) are frequently advocated as potential new management tools in this regard (Graham et al. 2011, Edgar et al. 2014).

No-take marine reserves are marine protected areas in which all extractive activities are prohibited. NTMRs may improve both fisheries management and conservation by spatially restricting fishing and other direct human impacts on fish stocks (Allison et al. 1998, Lubchenco et al. 2003). NTMRs can also protect marine biodiversity, enhance ecosystem health and services (Lubchenco et al. 2003, Edgar et al. 2014) and boost fisheries productivity (Sale et al. 2005) by reducing local overfishing and restoring 
natural processes in marine ecosystems and trophic food webs (McClanahan 1994, Babcock et al. 2010, McClanahan et al. 2011, Edgar et al. 2014).

Positive effects of NTMRs include significant increases in fish size, density, and biomass, or differences in fish assemblage structure in reserves compared to control (fished) sites. Many studies have demonstrated positive NTMR effects, especially for fisheries targeted species (Russ \& Alcala 2003, McClanahan et al. 2007, 2011), and while similar conclusions have been drawn from meta-analyses (Halpern 2003, Lester et al. 2009), NTMRs are not always effective (Sale et al. 2005, Guidetti et al. 2008).

NTMRs are usually not placed randomly, but may often be placed in areas of higher quality habitat, higher fish density, or greater biodiversity (Roberts et al. 2003). Alternatively, NTMRs may be placed in areas with poor habitat and low fish abundance, and consequently of low interest to fisheries to minimize negative social impacts (Roberts 2000, Edgar et al. 2004). Most studies of NTMR effects compare reserve and control sites post-implementation (Lester et al. 2009, Miller \& Russ 2014), potentially confounding reserve effects with spatial heterogeneity of habitat, larval supply, or pre-existing biological communities. The most robust methods for evaluating environmental and ecological impacts, including NTMR implementation, are before-after-controlimpact-pair (BACIP) designs (Jones et al. 1992, Russ 2002). If systematic differences in habitat exist between reserve and fished sites and such differences in habitat are not accounted for, conclusions about NTMR effectiveness may be inaccurate (Osenberg et al. 2006, 2011, Miller \& Russ 2014).

The potential for confounding habitat effects in NTMR studies is well recognized (Edgar \& Barrett 1997, Chapman \& Kramer 1999), but few studies have explicitly and adequately accounted for benthic habitat effects (McClanahan 1994, García-Charton \& Pérez-Ruzafa 1999, Osenberg et al. 2006). In a recent review of the NTMR literature, over half of NTMR studies made no statistical attempt to account for potential habitat effects on fish density or assemblage structure (Miller \& Russ 2014). Even smallscale differences in habitat may influence evaluations of reserve effects (Shears et al. 2006, Harmelin-Vivien et al. 2008). Some studies have analyzed NTMR effects with and without statistically correcting for habitat effects, and found that correcting for habitat effects can change the estimates and significance of NTMR effects (Chapman \& Kramer 1999, García-Charton et al. 2004, Miller et al. 2012), while others found no change (Russ et al. 2005). Differentiating NTMR and habitat effects, particularly changes to benthic habitat, is therefore a high priority for assessing the utility of NTMRs (Claudet \& Guidetti 2010).

Ecological interactions on coral reefs are typically described as operating via 1 of 2 general frameworks, top-down or bottom-up control, both of which may be acting concurrently (Wilson et al. 2008, Kellner et al. 2010). Top-down control emphasizes the role of higher trophic levels (e.g. predators) disproportionately influencing ecosystem processes and thereby shaping ecosystem function and community structure (McClanahan et al. 1999, 2011, Mumby et al. 2006, Graham et al. 2011). Prevalent research themes of top-down control on coral reefs include examinations of the effects of fishing pressure on fish communities (e.g. Jackson et al. 2001, McClanahan \& Arthur 2001, McClanahan et al. 2011), the role of predators shaping lower trophic levels (e.g. Heupel et al. 2014, Rizzari et al. 2014), and the functional role of herbivores grazing on benthic algal assemblages (Mumby et al. 2006, McClanahan et al. 2011, Humphries et al. 2014). Conversely, bottom-up control emphasizes that changes to habitat characteristics and/or the supply of nutrients shapes ecosystem function (e.g. Jones et al. 2004, Graham et al. 2011). However, few studies have examined the relative importance of top-down and bottom-up processes and how these affect different taxa in coral reef ecosystems (but see Smith et al. 2010, Ruppert et al. 2013). Nevertheless, many studies have documented top-down (trophic) effects, how these may affect the benthos, and how such effects are modified by NTMRs (Edgar et al. 2009, Babcock et al. 2010, Graham et al. 2011, McClanahan 2014).

Spatial and temporal variability of benthic habitat (e.g. quality, diversity, and extent) influence the distribution and density of reef fishes (Bellwood \& Hughes 2001). Specifically, physical structure and complexity of benthic habitat features (Chapman \& Kramer 1999, Hawkins et al. 2006) or live coral cover can affect fish density and species richness (Pratchett et al. 2012, Coker et al. 2014). Large changes in benthic habitat influence fish assemblage structure (Jones et al. 2004, Graham et al. 2006, Wilson et al. 2010). The relative influence of habitat and reserve effects vary across fish taxa (Russ \& Alcala 1998a, McClanahan \& Arthur 2001). As such, benthic habitat (e.g. coral cover, structural complexity) should be quantified and incorporated into NTMR assessments (Chapman \& Kramer 1999, Miller et al. 2012). Given that NTMR effects may often require decades to de- 
velop fully (McClanahan et al. 2007, Babcock et al. 2010, Russ \& Alcala 2010), it is desirable to assess such effects over the long-term.

This study examines the effects of NTMR status and benthic habitat on targeted and non-targeted reef fishes in well-enforced NTMRs in the Philippines using long-term monitoring and BACIP study designs, with consideration of potential trophic effects on fish density. Specifically, this study aims to assess the relative effects of NTMR status, benthic habitat, and trophic effects on the density and assemblage structure of targeted (lethrinid/ lutjanid) and non-targeted (pomacentrid) coral reef fishes. Targeted reef fishes were predicted to increase in density and change in assemblage structure in the NTMRs relative to fished controls over time with similar, but potentially smaller, effects on non-targeted reef fishes and live coral cover.

\section{MATERIALS AND METHODS}

\section{Study sites}

Five locally managed NTMRs and paired nonreserve (control, fished) sites were surveyed on small offshore islands in the central Philippines (Fig. 1, Table 1). All 10 sites, including reserve sites before reserve implementation, were heavily fished (Russ \& Alcala 1998a,b). Once implemented, NTMRs had high degrees of compliance (Alcala \& Russ 2006). All paired control sites were selected to be as similar as possible to reserve sites at each island. However, variable geomorphology meant that large differences in benthic habitat between reserve and control sites were largely unavoidable (Table 1).

At Apo and Sumilon reserves and non-reserves, fish densities were assessed 25 times over $30 \mathrm{yr}$, with NTMR protection ranging up to $31 \mathrm{yr}$ (Table 1). Details of environmental and management histories

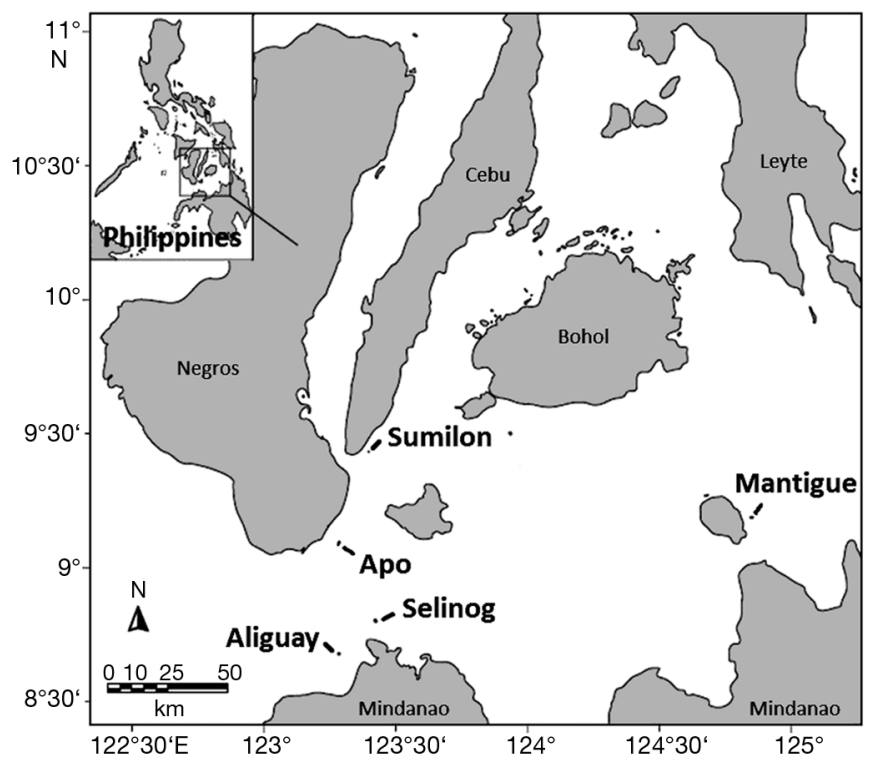

Fig. 1. Location of 5 small offshore islands in the central Philippines (Aliguay, Apo, Mantigue, Selinog, Sumilon) that had no-

take marine reserve and paired non-reserve (control) sites

Table 1. Description of no-take marine reserve (NTMR) and paired non-reserve sites surveyed in the central Philippines. Habitat characteristics are presented as mean $( \pm \mathrm{SE})$ values during the study (reserve values are in Roman and non-reserve in italic font). See 'Materials and methods' for description of structural complexity

\begin{tabular}{|c|c|c|c|c|c|c|c|c|c|}
\hline $\begin{array}{l}\text { Site } \\
\text { name }\end{array}$ & Municipality & City & Location & $\begin{array}{l}\text { Size } \\
\text { (ha) }\end{array}$ & $\begin{array}{l}\text { Island } \\
\text { geology }\end{array}$ & $\begin{array}{c}\text { Year } \\
\text { implemented }\end{array}$ & $\begin{array}{c}\text { Years } \\
\text { monitored }\end{array}$ & $\begin{array}{c}\% \text { Hard } \\
\text { coral }\end{array}$ & $\begin{array}{c}\text { Structural } \\
\text { complexity }\end{array}$ \\
\hline $\begin{array}{l}\text { Apo } \\
\text { Island }\end{array}$ & $\begin{array}{l}\text { Negros } \\
\text { Oriental }\end{array}$ & Dauin & $\begin{array}{c}9^{\circ} 4^{\prime} \mathrm{N} \\
123^{\circ} 16^{\prime} \mathrm{E}\end{array}$ & 22.5 & Granitic & $\begin{array}{l}\text { 1982, legal } \\
\text { in } 1986\end{array}$ & $\begin{array}{c}\text { 1983-2013, except: } \\
\text { 1984, 1986-1987, } \\
1989,1996,2002\end{array}$ & $\begin{array}{c}50.23 \pm 4.14 \\
32.83 \pm 3.88\end{array}$ & $\begin{array}{c}2.97 \pm 0.03 \\
2.01 \pm 0.02\end{array}$ \\
\hline $\begin{array}{l}\text { Sumilon } \\
\text { Island }\end{array}$ & Cebu & Oslob & $\begin{array}{l}9^{\circ} 21^{\prime} \mathrm{N} \\
123^{\circ} 23^{\prime} \mathrm{E}\end{array}$ & 37.5 & Coralline & 1974 & $\begin{array}{c}\text { 1983-2013, except: } \\
\text { 1984,1986-1987, } \\
1989,1996,2002\end{array}$ & $\begin{array}{c}31.53 \pm 1.49 \\
16.67 \pm 1.25\end{array}$ & $\begin{array}{c}3.33 \pm 0.05 \\
1.87 \pm 0.04\end{array}$ \\
\hline $\begin{array}{l}\text { Selinog } \\
\text { Island }\end{array}$ & $\begin{array}{l}\text { Zamboanga } \\
\text { del Norte }\end{array}$ & Dapitan & $\begin{array}{l}8^{\circ} 52^{\prime} \mathrm{N} \\
123^{\circ} 25^{\prime} \mathrm{E}\end{array}$ & 6 & Coralline & 2000 & $\begin{array}{c}1999-2001,2003 \\
2009\end{array}$ & $\begin{array}{c}15.15 \pm 2.27 \\
13.61 \pm 1.41\end{array}$ & $\begin{array}{c}2.00 \pm 0.09 \\
1.80 \pm 0.08\end{array}$ \\
\hline $\begin{array}{l}\text { Mantigue } \\
\text { Island }\end{array}$ & Camiguin & Mahinog & $\begin{array}{l}9^{\circ} 10^{\prime} \mathrm{N} \\
124^{\circ} 49^{\prime} \mathrm{E}\end{array}$ & 3.6 & Coralline & 2000 & $\begin{array}{c}1999,2001,2003 \\
2007\end{array}$ & $\begin{array}{c}36.94 \pm 3.81 \\
19.81 \pm 4.02\end{array}$ & $\begin{array}{c}2.90 \pm 0.02 \\
1.90 \pm 0.09\end{array}$ \\
\hline $\begin{array}{l}\text { Aliguay } \\
\text { Island }\end{array}$ & $\begin{array}{l}\text { Zamboanga } \\
\text { del Norte }\end{array}$ & Dapitan & $\begin{array}{c}8^{\circ} 45^{\prime} \mathrm{N} \\
123^{\circ} 13^{\prime} \mathrm{E}\end{array}$ & 20 & Coralline & 2005 & 1999,2000 & $\begin{array}{c}28.75 \pm 0.92 \\
32.63 \pm 3.21\end{array}$ & $\begin{array}{r}1.67 \pm 0.02 \\
2.53 \pm 0.13\end{array}$ \\
\hline
\end{tabular}


of Sumilon and Apo Islands are provided in Alcala \& Russ (2006). Environmental disturbances, including coral bleaching, typhoons, storms, crown-of-thorns starfish (COTS) outbreaks and destructive fishing caused large changes to benthic habitat during the study, but were usually followed by periods of coral recovery. Sumilon reserve and non-reserve sites have a complex history of management. The reserve was established in 1974 and monitoring of reef fish densities began in 1983. NTMR protection was removed at Sumilon reserve from 1984 to 1986 and 1992 to 1994. All fishing gears except hook-and-line were banned in 1995-1998. The Sumilon nonreserve site was made no-take from 1987 to 1991 and only hook-and-line was permitted from 2009 to 2013. Therefore, only the years 1995-2008 were examined in statistical models to determine the effect of NTMR protection at Sumilon. Selinog, Mantigue and Aliguay Islands were surveyed 5, 4 and 2 times, respectively (Table 1). These disturbances and changes in management provided a unique opportunity to examine long-term effects of orthogonal changes in NTMR protection and benthic habitat on fish density and assemblage structure.

\section{Study species}

Thirty species of coral reef fishes from 3 families were examined (Table 2): Lethrinidae (emperors), Lutjanidae (snappers), and Pomacentridae (damselfishes). Lethrinids and lutjanids were examined together as fishery-targeted taxa, and only large individuals ( $>10 \mathrm{~cm}$ total length [TL]) and large species ( $\geq 40 \mathrm{~cm}$ maximum TL) were included to ensure fishery target status. All 10 species of lethrinids and lutjanids are equally targeted by fishers, and equally vulnerable to fishing gears (hook-and-line, traps, spear and gill nets). However, these species vary in dietary preferences, often consuming a combination of fish and invertebrates. The 20 most locally abundant species of pomacentrids were surveyed. Pomacentrids were selected as a non-targeted group because they are small (generally 5-10 cm TL) and rarely captured in reef fisheries regionally. Species of Lethrinidae and Lutjanidae are known to prey on small teleost fishes (Kulbicki et al. 2005) and have been categorized as predators of damselfish (Thresher 1983). Given this, there is the potential for a trophic interaction as lutjanids and lethrinids represent potential predators of damselfish.

Underwater visual census was conducted by a single observer (G. R. Russ) on 6 replicate transects $(50 \times$
Table 2. Species used in this study of no-take marine reserve and benthic habitat effects, including large targeted Lethrinidae (emperors, 5 species) and Lutjanidae (snappers, 5 species), and non-targeted Pomacentridae (damselfishes, 20 species)

\begin{tabular}{|ll|}
\hline Taxon/species & Taxon/species \\
\hline Lethrinidae & Pomacentridae \\
Lethrinus atkinsoni & Abudefduf vaigiensis \\
L. erythracanthus & Amblyglyphidodon aureus \\
L. harak & A. curacao \\
L. obsoletus & A. leucogaster \\
Monotaxis grandoculis & Chromis amboinensis \\
& C. retrofasciata \\
Lutjanidae & C. ternatensis \\
Lutjanus argentima- & C. viridis \\
culatus & C. weberi \\
L. bohar & Chrysiptera talboti \\
L. gibbus & Dascyllus aruanus \\
L. monostigma & D. reticulatus \\
L. rivulatus & D. trimaculatus \\
& Dischistodus melanotus \\
& Plectroglyphidodon lacrymatus \\
& Pomacentrus amboinensis \\
& P. brachialis \\
& P. coelestis \\
& P. lepidogenys \\
& P. moluccensis \\
\hline
\end{tabular}

$20 \mathrm{~m}$ ) per site on the reef slope (3-17 m) in November or December of each sampling year. Replicates were placed at the same depth and within $5-10 \mathrm{~m}$ of the previous location. Lethrinid/lutjanid densities were recorded as individuals per $1000 \mathrm{~m}^{2}$ and pomacentrids in $\log _{4}$ abundance categories per $1000 \mathrm{~m}^{2}$ following Russ \& Alcala (1998a,b), with total pomacentrid density estimated from category midpoints (Categories 16 ) or minimum values (Categories 7-8).

\section{Benthic composition and habitat complexity}

From 1999 onwards, each $1000 \mathrm{~m}^{2}$ replicate was divided into ten $10 \times 10 \mathrm{~m}$ benthic quadrats. Substrata in each quadrat were estimated by eye as percent cover (to $5 \%$ ) and categorized into hard coral ( $\mathrm{HC}_{\text {; }}$ branching, massive, and encrusting coral), soft coral (SC), and dead substrate (DS; sand, rubble, and bare or hard dead substrate). A structural complexity index (SCI) and reef slope steepness were estimated visually on semi-quantitative scales from 0 (low SCI, horizontal slope) to 4 (high SCI, vertical slope). Prior to 1999, a line-intercept transect (50 m long) method was used to estimate cover of benthic substrata, but not SCI or reef slope, which were 'back-estimated' using a predictive relationship developed by Russ et al. (2005). 


\section{Data analysis}

Density estimates of individual pomacentrid species were retained in $\log _{4}$ categories, and density estimates of lethrinids/lutjanids and total pomacentrid densities were $\log _{10}(x+1)$ transformed to meet assumptions of normality and homogeneity of variances. Fish assemblage data from years in which habitat variables were not collected were excluded from general linear mixed model (GLMM) analyses (1988, 1990-1992 at Apo reserve, Apo non-reserve and Sumilon non-reserve), but were included for multidimensional scaling analysis (MDS) of the fish assemblages. For Sumilon Island, the years in which the reserve was open to fishing or the non-reserve closed to fishing were excluded from GLMM analyses but included in graphical plots.

The effects of NTMR protection and benthic habitat on fish density and the effects of NTMR protection on total hard coral cover were investigated using GLMM. Separate GLMMs were performed for Apo, Sumilon, Mantigue, and Selinog Islands. For GLMMs on targeted and non-targeted species, status (reserve or non-reserve), time, and benthic characteristics (HC, SC, DS, SCI, and slope) were treated as fixed effects, while replicate transects were treated as a random factor. For total hard coral cover, GLMMs were used with status and time treated as fixed effects, while replicate transects were treated as a random factor. A significant time (duration of protection) $\times$ NTMR status (reserve or non-reserve) interaction was considered to demonstrate a reserve effect provided that fish density or coral cover increased in the reserve but not in the control site over time.

Multi-model inferences were based on the corrected Akaike's information criterion (AICc; Burnham \& Anderson 2002, 2004). The smallest AICc value identified the model with the greatest support. Relative support for one model was determined by calculating the differences between its $\mathrm{AICC}$ and the smallest $\mathrm{AICC}$ $(\triangle \mathrm{AICC})$ and scaling these differences into model weights (wAICc). Based on these model weights, model-averaged coefficients were calculated with associated standard errors and $\mathrm{p}$-values for each predictor. Models with values of $\triangle \mathrm{AICC} \leq 2$ were selected for model averaging because Burnham \& Anderson (2004) suggest that these models have the most support. Analyses were carried out in R (R Core Team 2012) using the nlme and MuMin packages for the GLMMs and multi-model inference, respectively. Model-averaged coefficients are reported in the Results and top models used in model averaging are summarized in Table S1 in the Supplement (see www. int-res.com/articles/suppl/m529p233_supp.pdf).
Boosted regression trees (BRTs) were used to examine the relative influence of top-down versus bottom-up effects on the density of non-targeted species (i.e. potential prey) and targeted species (i.e. potential predators) in relation to benthic variables across the same 4 islands (pooled) from the GLMMs. BRT benthic variables were included based on identification in the top models or significant results in the GLMMs and their biological relevance (i.e. HC, SC, DS, SCI, slope, prey density, or predator density). Models were fitted separately for targeted and nontargeted species. BRTs are tree-based models that relate a response variable to multiple predictors using recursive partitioning with the advantage of improved predictive performance via boosting (De'ath 2007, Elith et al. 2008). Reserve protection variables were excluded from BRTs as they were investigated in each island-specific GLMM. Optimal tree complexity, learning rate, and bag fraction were determined following Elith et al. (2008). Tree complexity refers to the number of times each tree divides at each iteration, and was restricted to 5 divisions to reduce over-fitting potential. Learning rate was kept low (0.01) to reduce the effects of the primary set of trees on the final solutions and the optimal number of trees was kept close to 1000 to reduce among-model variance (Elith et al. 2008). Bag fractions, the percentage of the dataset used in the BRT model, were tested between 0.5 and 0.8 , and the model that explained the greatest deviance between predicted and observed values was used in the final analysis (c.f. Sutcliffe et al. 2014). The relative influence of predictor variables was calculated as the reduction in the sum-of-squares error in the training dataset attributable to each variable in predicting the response at each iteration, normalized to sum to 100 (Ridgeway 2006). Each predictor was ranked in comparison to other predictors and predictor variables were identified that consistently had higher relative influence in the models. Results were validated using 10-fold cross-validation methods (Elith et al. 2008). All BRT models were fitted with $\mathrm{R}$ (R Core Team 2012), using the package gbm and additional custom code (Elith et al. 2008).

The structure of this dataset necessitated incorporation of replicate transects as random factors to effectively control for the lack of independence among replicates that were sampled at the same site over successive years. Therefore, cross-validation methods were used to account for random factors (Fabricius \& De'ath 2008). To test whether the cross-validation methods succsessfully fitted a model of the response that accounted for the majority of variation in non- 
targeted and targeted species density, we tested the relationship between replicate transects and the residuals of the models using methods described by Wood (2006). This involved modelling the residuals as: (1) a linear null model and (2) a linear null model with replicate transect as a random effect, but no fixed effects. An ANOVA comparing the 2 models indicated no replicate transect-based patterns in the residuals for either non-targeted or targeted species density.

Principal component analysis was used to examine patterns of habitat variation and NTMR protection at the site level (all 6 replicate transects at a reserve or non-reserve) across all 5 islands and all times. Percent benthic cover data were arcsine square-root transformed whereas SCI, duration of NTMR protection, and lethrinid/lutjanid densities were $\log _{10}(x+1)$ transformed, to meet assumptions of normality and homogeneity of variances. Apo reserve 2012 and 2013 (outliers caused by a typhoon effect on the benthos) were retained as their removal did not change trends in the principal component analysis. Non-metric MDS was used to investigate site-level patterns in fish assemblage structure. MDS plots were created based on Bray-Curtis similarity matrices and a dummy variable was included for lethrinid/lutjanid densities. Cluster analyses based on group averages were performed on the similarity matrices, and relationships were tested for significance using SIMPROF permutation testing (Clarke \& Warwick 2001). MDS plots were overlayed with slices of cluster dendrograms to demonstrate significantly similar groups. Vectors indicated species with a correlation value $>60 \%$ (lethrinids/lutjanids) or $>75 \%$ (pomacentrids) from sites within the multivariate structure.

Relationships between fish assemblage structure and benthic data were assessed via the BEST BIOENV routine in PRIMER. Using a Spearman rank correlation, habitat data and fish assemblage matrices were compared, allowing identification of the variable(s) that explained the greatest variance in fish assemblages (Clarke \& Warwick 2001) with significance tested with 999 permutations. Six variables were considered: (1) years of NTMR protection, (2) reef slope, (3) structural complexity, (4) dead substrate cover, (5) hard coral cover, and (6) soft coral cover.

\section{RESULTS}

\section{NTMR effects}

Densities of targeted lethrinids/lutjanids increased markedly over time in NTMRs relative to fished controls at all 4 islands (Fig. 2). Although initially similar between NTMR and fished control sites, the density of target species increased over time to be higher in NTMRs than fished sites by factors of 5.5 (Apo, 29 yr), 4.5 (Sumilon, 14 yr), 8 (Selinog, 9.5 yr), and 75 (Mantigue, 7.5 yr; Fig. 2). A significant time $\times$ NTMR status interaction was observed at 2 islands (Apo, Sumilon) and this interaction was included in the top model for a third island (Mantigue; Table 3). At Selinog reserve, a strong increase in density of targeted fishes inside the NTMR and no increase in the fished site was clear (Fig. 2), but there was no significant time $\times$ NTMR status interaction in the model (Table 3). Apo, Mantigue, and Selinog showed significant habitat effects on the density of targeted species. When the GLMMs for Selinog and Mantigue were rerun excluding habitat variables, both islands had significant time $\times$ NTMR status interactions, consistent with strong reserve effects on target species (Selinog: $z=2.7, \mathrm{p}=0.01$; Mantigue: $z=3.16, \mathrm{p}<$ 0.01). This result, replicated at 4 separate islands, demonstrates a clear and strong NTMR effect on these target species.

In contrast, densities of non-target pomacentrids generally showed no clear responses to NTMR protection (Table 3, Fig. 2). That is, there were no clear divergences of density between NTMR and fished sites over time except at Mantigue (Fig. 2). Habitat variables (e.g. cover of $\mathrm{HC}, \mathrm{SC}, \mathrm{DS}$, and angle of reef slope) were identified as significant predictors of pomacentrid density at all 4 islands, and were also consistently selected in the top models (Table 3). Inspection of pomacentrid densities over time indicated strong correlations with hard coral cover at all 4 islands (Fig. 2). However, no strong relationships with duration of reserve protection could be detected, either statistically or through examination of temporal trends (Fig. 2). Selinog reserve was the only island that had a significant time $\times$ NTMR status interaction (Table 3), but no clear increase in non-targeted fish density inside the reserve relative to the control site was observed (Fig. 2).

A significant time $\times$ NTMR status interaction was observed for hard coral cover at all islands (Table 3 ). However, a consistent increase in hard coral cover in the reserve compared to the non-reserve was not observed at any island (Fig. 2), suggesting no real reserve effect on hard coral cover. A decrease of hard coral cover at Mantigue non-reserve relative to the reserve over time was caused by a COTS outbreak in 2003 that affected only the non-reserve site. 
A
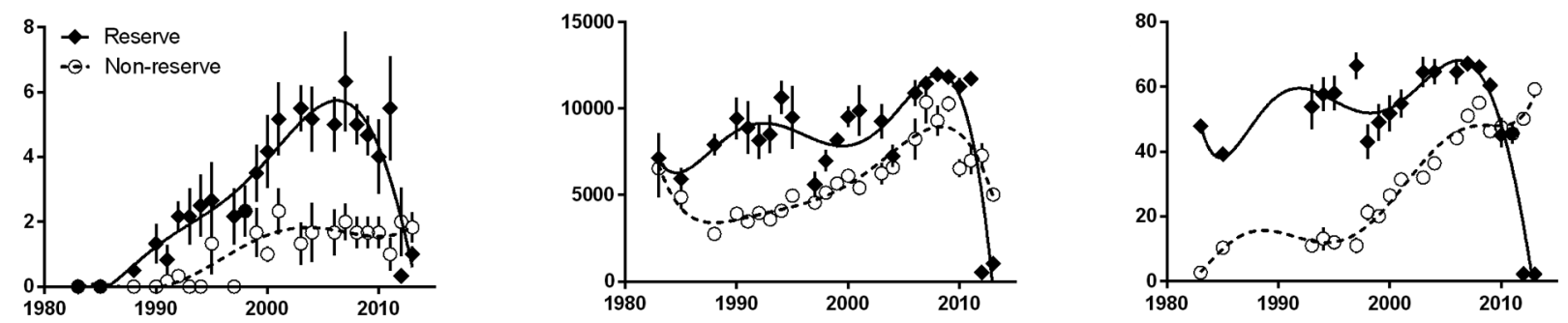

B
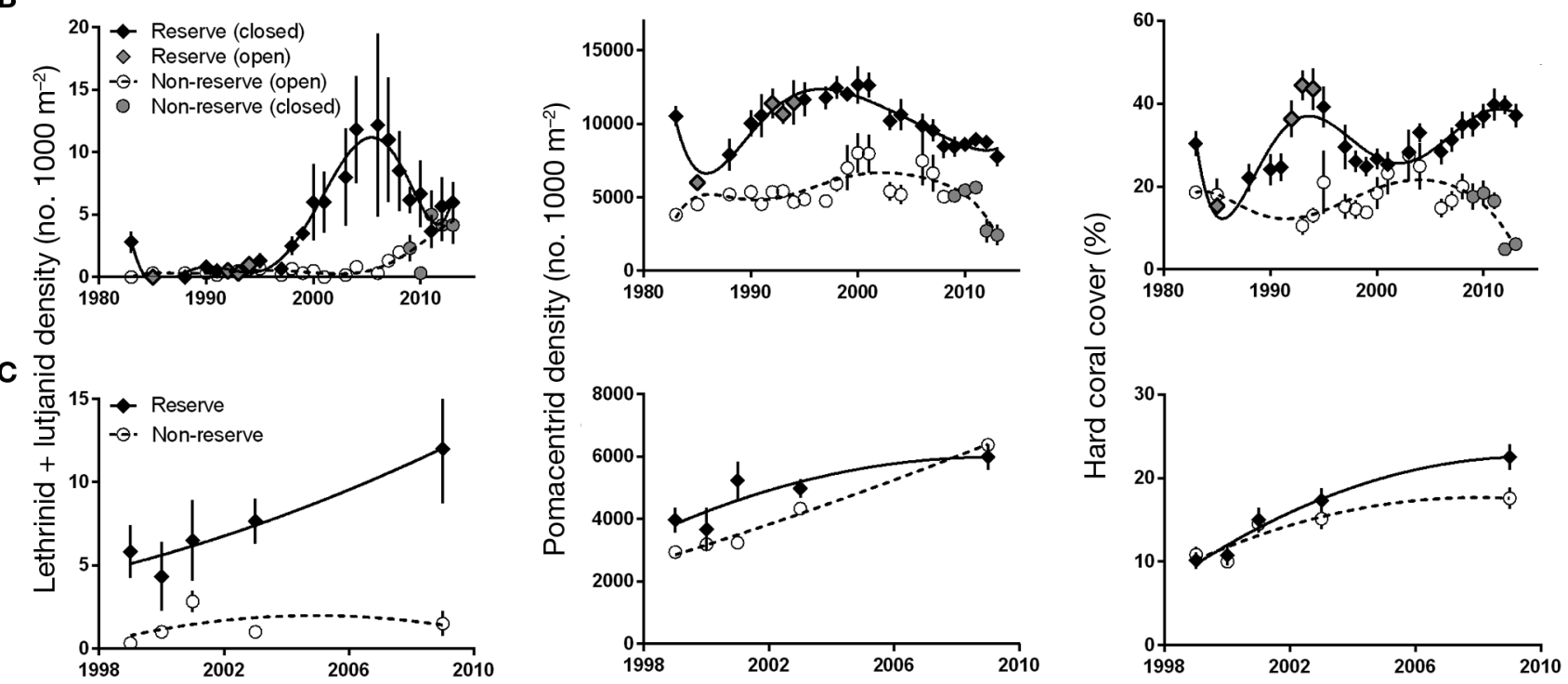

D
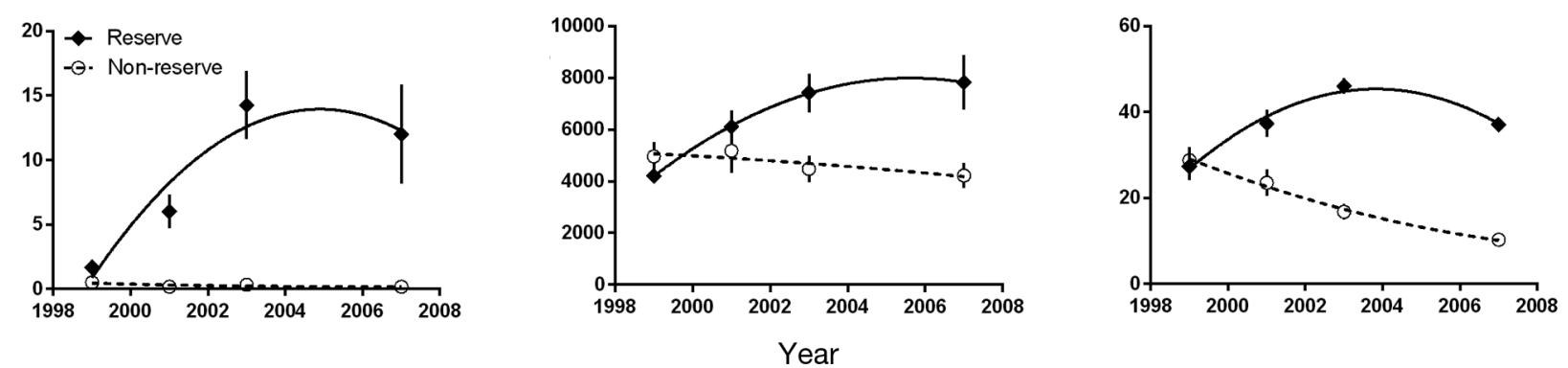

Fig. 2. Changes in density (mean $\pm \mathrm{SE}$ ) of targeted lethrinids/lutjanids (left column), non-targeted pomacentrids (middle column), and hard coral cover (right column) inside 4 no-take marine reserves (NTMRs; black diamonds and solid lines) and at fished control sites (white circles and dashed lines) at (A) Apo, (B) Sumilon, (C) Selinog, and (D) Mantigue Islands. Trends are fitted with polynomial regressions. Grey symbols at Sumilon Island represent data points when Sumilon reserve was open to fishing and when Sumilon non-reserve was closed to fishing

\section{Relative influence of top-down, bottom-up and benthic effects}

BRTs indicated that, independent of the strong NTMR effect (Fig. 2), percent cover of HC had the highest relative influence $(22 \%)$ on density of target species, with density of potential prey having a relative influence of $17 \%$ (Fig. 3). Density of target species increased with increasing $\mathrm{HC}$ cover, reef slope, and potential prey density (Fig. 3). For density of non-targeted species, SC had the greatest relative influence $(53 \%)$, and density of predators had very little relative influence (5\%; Fig. 4). Density of nontargeted species decreased with percent cover of SC and was highest at intermediate levels of SCI (Fig. 4A). The total deviance explained by BRT models of targeted and nontargeted fish density (Figs. 3 $\& 4$ ), across all islands and years, was $43 \%$ and $71 \%$, respectively, and the overall predictive performance (cross-validation Spearman correlation) for targeted 
Table 3. Model-averaged coefficient estimates, standard errors, $z$-values, and associated p-values for predictors of targeted species (lethrinids and lutjanids) density, non-targeted species (pomacentrids) density, and total hard coral cover at Apo, Sumilon, Mantigue, and Selinog Islands. Reserve status effects are relative to fished areas. Bold p-values are significant at the 0.05 level, and effects in bold are those identified in the top-ranked model (i.e. lowest AICc value; Table S1). Table S1 summarizes the top models used in averaging. DS: dead substratum cover; HC: hard coral cover; SC: soft coral cover; SCI: structural complexity

\begin{tabular}{|c|c|c|c|c|c|c|}
\hline Variable & Location & Effect & Estimate & SE & $z$-statistic & $\mathrm{p}$ \\
\hline \multirow[t]{26}{*}{ Targeted species } & Apo (1985-2013) & Intercept & 217.82 & 107.61 & 2.01 & 0.044 \\
\hline & & Status & -554.22 & 138.5 & 3.98 & $<0.001$ \\
\hline & & Time & -0.11 & 0.05 & 1.99 & 0.046 \\
\hline & & Status $\times$ Time & 0.28 & 0.07 & 4.02 & $<0.001$ \\
\hline & & HC & 0.08 & 0.02 & 5.05 & $<0.001$ \\
\hline & & $\mathrm{SC}$ & -0.03 & 0.05 & 0.51 & 0.61 \\
\hline & & DS & -0.05 & 0.04 & 1.35 & 0.18 \\
\hline & & Slope & -8.74 & 13.08 & 0.67 & 0.51 \\
\hline & Sumilon (1995-2008) & Intercept & -264.00 & 529.70 & 0.49 & 0.62 \\
\hline & & Status & -1813.00 & 717.10 & 2.50 & 0.01 \\
\hline & & Time & 0.13 & 26.46 & 0.49 & 0.62 \\
\hline & & Status $\times$ Time & 0.91 & 0.36 & 2.51 & 0.01 \\
\hline & & $\mathrm{HC}$ & 0.05 & 0.07 & 0.64 & 0.52 \\
\hline & Mantigue (1999-2007) & Intercept & -993.30 & 678.00 & 1.43 & 0.15 \\
\hline & & Status & -1035.00 & 1071.00 & 0.95 & 0.34 \\
\hline & & Time & 0.49 & 0.34 & 1.43 & 0.15 \\
\hline & & Status $\times$ Time & 0.83 & 0.45 & 1.80 & 0.07 \\
\hline & & HC & 0.17 & 0.06 & 2.70 & $<0.01$ \\
\hline & & SC & -0.32 & 0.19 & 1.58 & 0.11 \\
\hline & & DS & -0.13 & 0.06 & 1.99 & 0.047 \\
\hline & Selinog (1999-2009) & Intercept & -113.59 & 243.54 & 0.46 & 0.65 \\
\hline & & Status & 6.92 & 0.93 & 7.24 & $<0.001$ \\
\hline & & Time & 0.18 & 0.15 & 1.18 & 0.24 \\
\hline & & $\mathrm{HC}$ & 0.38 & 0.24 & 1.57 & 0.12 \\
\hline & & SC & -0.72 & 0.20 & 3.48 & $<0.001$ \\
\hline & & DS & -0.11 & 0.32 & 0.35 & 0.73 \\
\hline \multirow{13}{*}{$\begin{array}{l}\text { Non-targeted } \\
\text { species }\end{array}$} & Apo (1985-2013) & Intercept & 7.83 & 2.03 & 3.84 & $<0.001$ \\
\hline & & Status & 3.92 & 4.88 & 0.80 & 0.42 \\
\hline & & $\mathrm{HC}$ & 0.03 & 0.01 & 2.02 & 0.043 \\
\hline & & SC & 0.02 & 0.01 & 1.68 & 0.09 \\
\hline & & DS & -0.001 & 0.03 & 0.05 & 0.96 \\
\hline & & $\mathrm{SCI}$ & 0.17 & 0.20 & 0.86 & 0.39 \\
\hline & & Slope & -1.98 & 2.43 & 0.82 & 0.41 \\
\hline & Sumilon (1995-2008) & Intercept & 10.66 & 7.63 & 1.39 & 0.17 \\
\hline & & Status & 0.45 & 0.07 & 6.58 & $<0.001$ \\
\hline & & Time & -0.01 & 0.007 & 0.81 & 0.42 \\
\hline & & DS & -0.01 & 0.003 & 2.54 & 0.01 \\
\hline & & $\mathrm{SCI}$ & 0.15 & 0.11 & 1.37 & 0.17 \\
\hline & & Slope & 0.45 & 0.07 & 6.59 & $<0.001$ \\
\hline \multirow[t]{12}{*}{-} & Mantigue (1999-2007) & Intercept & -53.34 & 33.59 & 1.56 & 0.12 \\
\hline & & Time & 0.03 & 0.01 & 2.37 & 0.02 \\
\hline & & $\mathrm{HC}$ & 0.02 & 0.01 & 2.53 & 0.01 \\
\hline & & SC & 0.02 & 0.01 & 1.71 & 0.09 \\
\hline & & DS & -0.01 & 0.006 & 1.80 & 0.07 \\
\hline & Selinog (1999-2009) & Intercept & -169.90 & 23.16 & 7.16 & $<0.001$ \\
\hline & & Status & 126.30 & 30.68 & 4.01 & $<0.001$ \\
\hline & & Time & 0.09 & 0.01 & 7.51 & $<0.001$ \\
\hline & & Status $\times$ Time & -0.06 & 0.02 & 4.00 & $<0.001$ \\
\hline & & $\mathrm{HC}$ & 0.02 & 0.02 & 1.27 & 0.21 \\
\hline & & $\mathrm{SC}$ & -0.04 & 0.01 & 3.78 & $<0.001$ \\
\hline & & DS & 0.01 & 0.02 & 0.34 & 0.74 \\
\hline \multirow[t]{14}{*}{ Hard coral cover } & Apo (1985-2013) & Intercept & -4542.29 & 425.81 & -10.67 & $<0.001$ \\
\hline & & Status & 7009.81 & 612.62 & 11.44 & $<0.001$ \\
\hline & & Time & 2.29 & 0.21 & 10.75 & $<0.001$ \\
\hline & & Status $\times$ Time & -3.49 & 0.31 & -11.41 & $<0.001$ \\
\hline & Sumilon (1995-2008) & Intercept & 19.70 & 1.28 & 15.42 & $<0.001$ \\
\hline & & Status & 10.01 & 1.77 & 5.70 & $<0.001$ \\
\hline & Mantigue (1999-2007) & Intercept & 4675.63 & 876.13 & 5.34 & $<0.001$ \\
\hline & & Status & -6633.57 & 1239.90 & -5.35 & $<0.001$ \\
\hline & & Time & -2.33 & 0.44 & -5.31 & $<0.001$ \\
\hline & & Status $\times$ Time & 3.32 & 0.62 & 5.36 & $<0.001$ \\
\hline & Selinog (1999-2009) & Intercept & -1365.47 & 326.35 & -4.18 & $<0.001$ \\
\hline & & Status & -1075.91 & 461.28 & -2.33 & 0.02 \\
\hline & & Time & 0.69 & 0.16 & 4.23 & $<0.001$ \\
\hline & & Status $\times$ Time & 0.54 & 0.23 & 2.34 & 0.02 \\
\hline
\end{tabular}



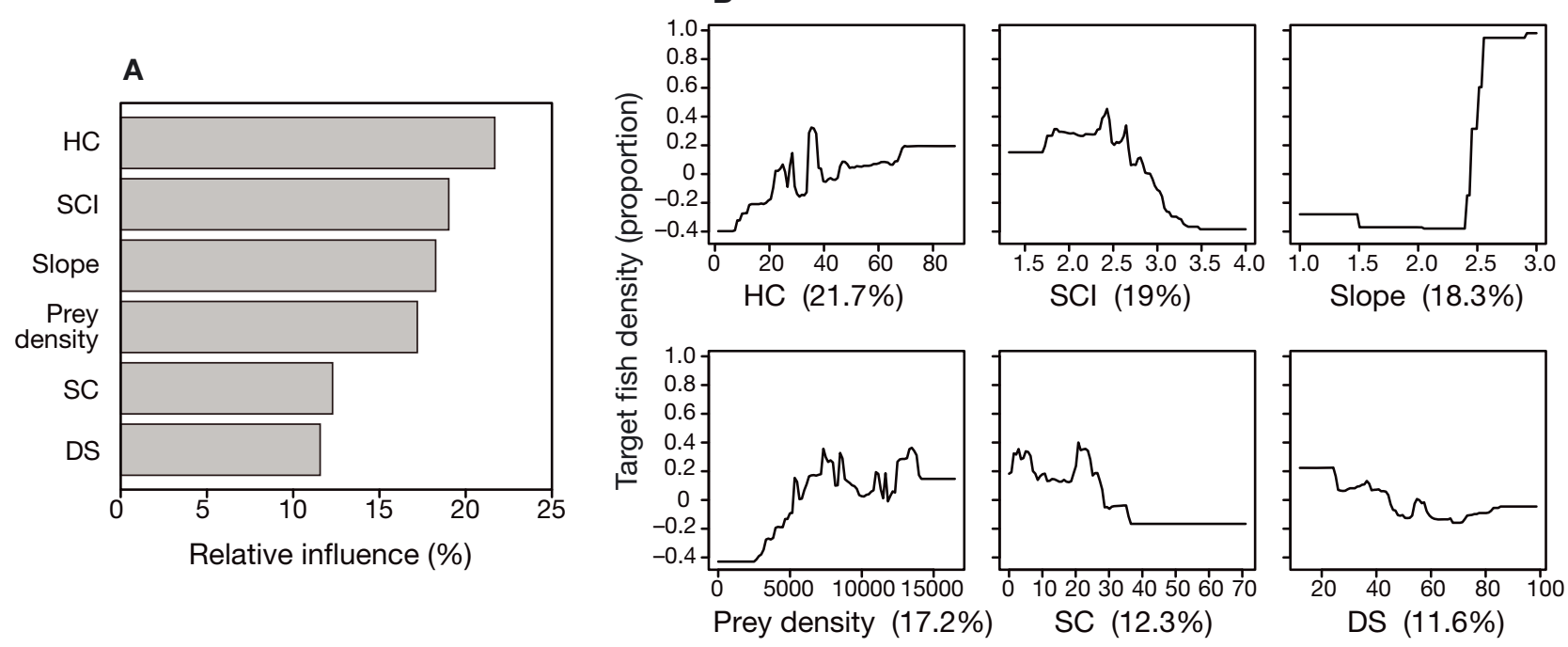

Fig. 3. Contributions of benthic predictor variables and potential prey (i.e. non-targeted species) density on targeted species density. (A) Relative influence (\%) of hard coral cover (HC), slope, structural complexity index (SCI), prey density, soft coral cover (SC), and dead substrate cover (DS) on targeted species density. (B) Partial plots of potential prey (i.e. non-targeted species) density and benthic variables in boosted regression tree (BRT) models for targeted species density. Relative contributions of variables to the BRT models are shown in parentheses
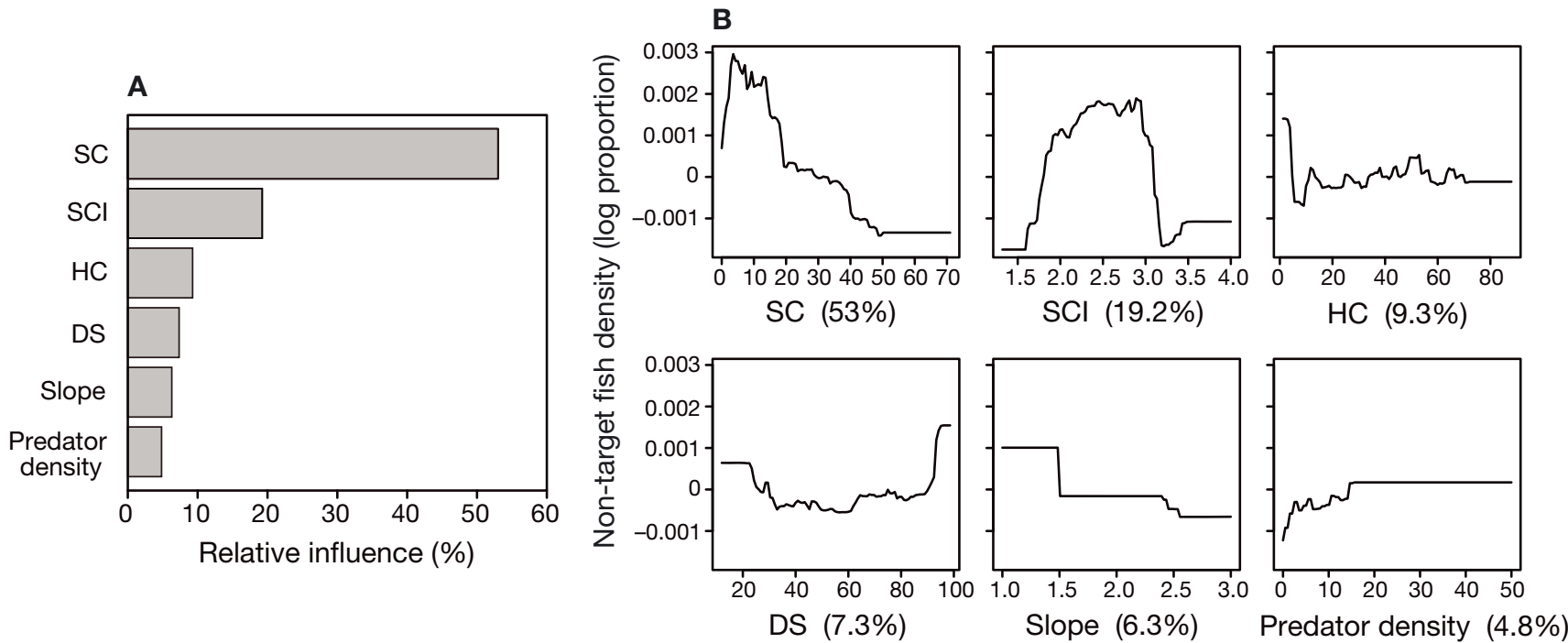

Fig. 4. Contributions of benthic predictor variables and potential predator (i.e. targeted species) density on non-targeted species density. (A) Relative influence (\%) of soft coral cover (SC), structural complexity (SCI), hard coral cover (HC), dead substrate cover (DS), slope, and predator (i.e. targeted species) density on non-targeted species density. (B) Partial plots of potential predator (i.e. targeted species) density and benthic variables in boosted regression tree (BRT) models for non-targeted species density. Relative contributions of variables to the BRT models are shown in parentheses

and non-targeted density was $0.57 \pm 0.04$ and $0.84 \pm$ 0.01 (means $\pm \mathrm{SE}$ ), respectively.

\section{Benthic habitats at each site}

Principal component analyses indicated strong differentiation of benthic habitat, which tended to be very consistent over time (Fig. 5). The principal divi- sion of sites was between reserves and non-reserves, with reserves typically characterized by higher reef slope, SCI, and cover of HC (e.g. Sumilon, Apo, and Mantigue NTMRs), while most non-reserves and Selinog reserve were characterized by a high cover of DS, low SCI, and gradual reef slopes (Fig. 5, Table 1). Apo non-reserve was somewhat unique in having (until 1998) high cover of SC, a gradual reef slope, and low SCI (Fig. 5, Table 1). The benthic 


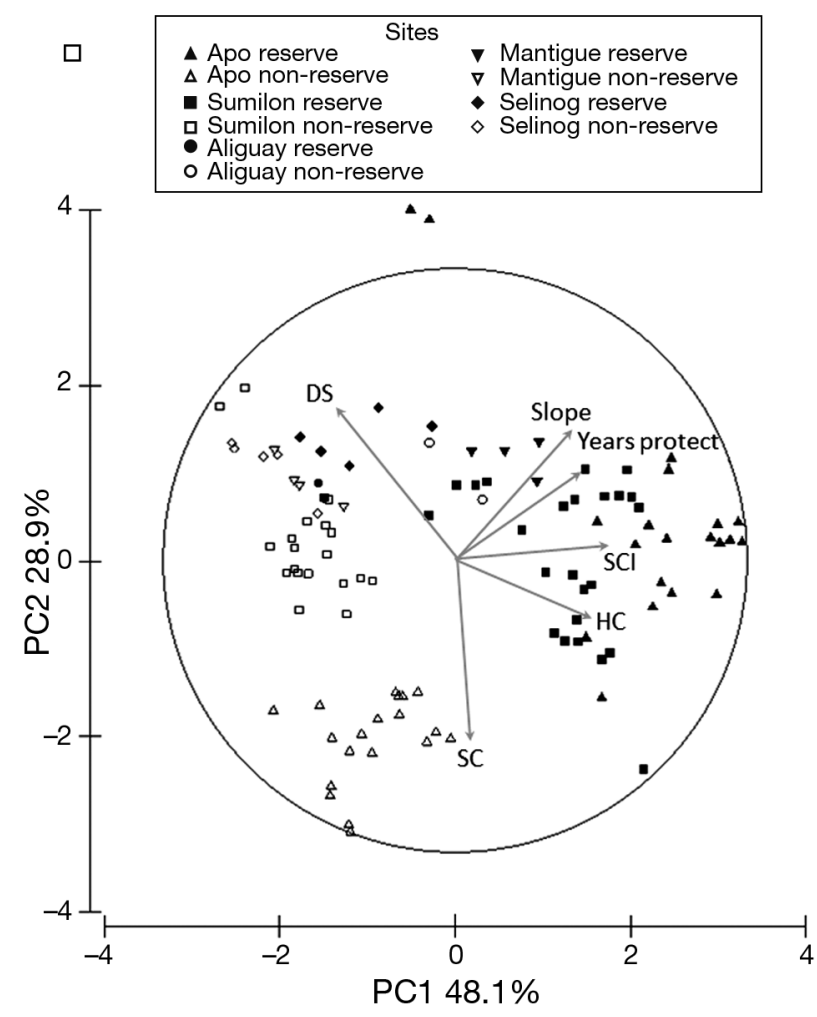

Fig. 5. Correlation-based principal component (PC) analysis of transformed benthic habitat and no-take marine reserve (NTMR) status variables across 5 paired NTMR and control sites through time (see Table 1 for years surveyed at each site) in the central Philippines. DS: dead substratum cover; HC: hard coral cover; SC: soft coral cover; SCI: structural complexity

habitat at Apo reserve in 2012 and 2013 differentiated from all other years and sites (solid triangle outliers, top centre in Fig. 5) due to the effects of typhoons Washi (2011) and Bopha (2012).

\section{Assemblage structure of reef fish}

The non-targeted pomacentrid assemblage displayed a clear division in multivariate space based on MDS and cluster analyses (70\% similarity; Fig. 6, Fig. $\mathrm{S} 1$ in the Supplement). There was a distinct pomacentrid assemblage at sites associated with high cover of DS and low SCI (Sumilon, Mantigue, and Selinog non-reserves, and the proposed Aliguay reserve; left side, Fig. 6). This assemblage was characterized by high density of 2 species of Dascyllus (both abundant on gradual slopes with high cover of DS) and Plectroglyphidodon lacrymatus (Fig. 6). There was another distinct assemblage associated with sites with high cover of $\mathrm{HC}$ and high SCI (Apo,
Mantigue, Selinog, and Sumilon reserves, and Apo and Aliguay non-reserves). This assemblage was characterized by high density of 3 species of planktivorous Chromis and 2 species of Amblyglyphidodon (all characteristic of steep, complex reef slopes with high coral cover), plus 1 species of Pomacentrus characteristic of areas with high cover of HC. Three site-time combinations, Apo Reserve 2012 and 2013 and Sumilon non-reserve 2013, differentiated from other sites (upper left solid ellipse, Fig. 6); all 3 were adversely affected by typhoons, particularly Bopha in 2012. The strong influence of benthic habitat on pomacentrid assemblage structure is suggested in the similar differentiation among sites in multivariate space of the benthos (Fig. 5) and the non-targeted pomacentrids (Fig. 6). If pomacentrids responded to direct NTMR effects, this would be detected as assemblages in reserve and control sites become increasingly separated in multivariate space over time, but this was not observed.

\begin{tabular}{|lll|}
\hline Apo reserve & Sites & \\
$\Delta$ Apo non-reserve & $\nabla$ & Mantigue reserve \\
Sumilon reserve & Seligue non-reserve \\
Sumilon non-reserve & $\diamond$ Selinog non-reserve \\
- Aliguay reserve & \\
O Aliguay non-reserve & \\
\hline
\end{tabular}

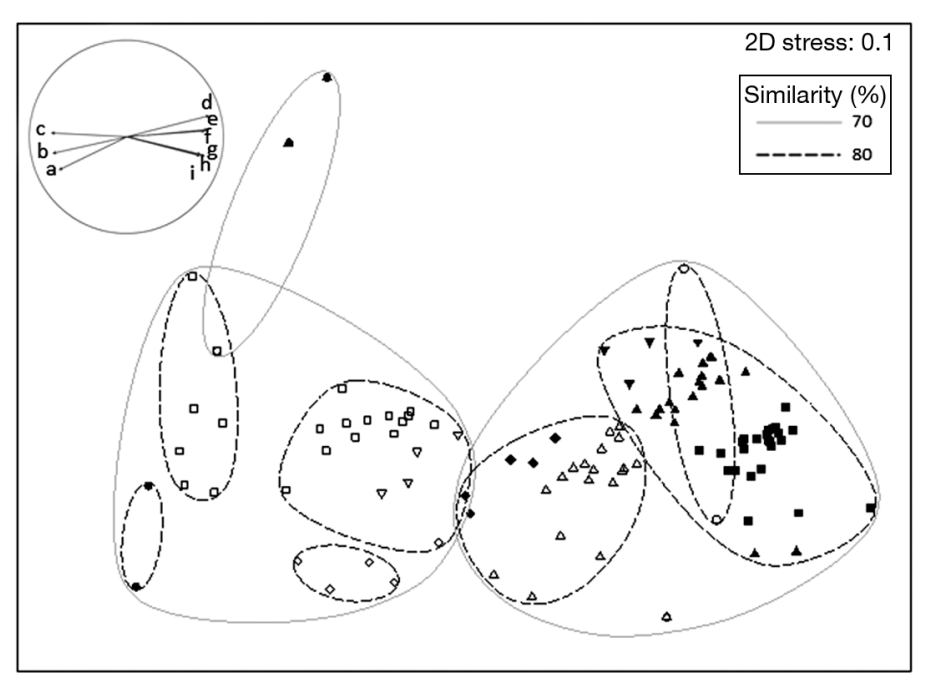

Fig. 6. Non-metric multi-dimensional scaling (MDS) plot based on Bray-Curtis similarity for density of 20 species of Pomacentridae at 5 paired no-take marine reserve and control sites over time (see Table 1 for years surveyed at each site) in the central Philippines between 1983 and 2013. Ellipses represent $70 \%$ (solid lines) and $80 \%$ (dashed lines) similarity from cluster analysis (based on Bray-Curtis similarity matrix). Inset indicates species vectors with a correlation $>75 \%$. a: Dascyllus reticulatus; b: D. trimaculatus; c: Plectroglyphidodon lacrymatus; d: Chromis ternatensis; e: C. amboinensis; f: C. retrofasciata; g: Pomacentrus moluccensis; h: Amblyglyphidodon leucogaster; i: A. aureus 

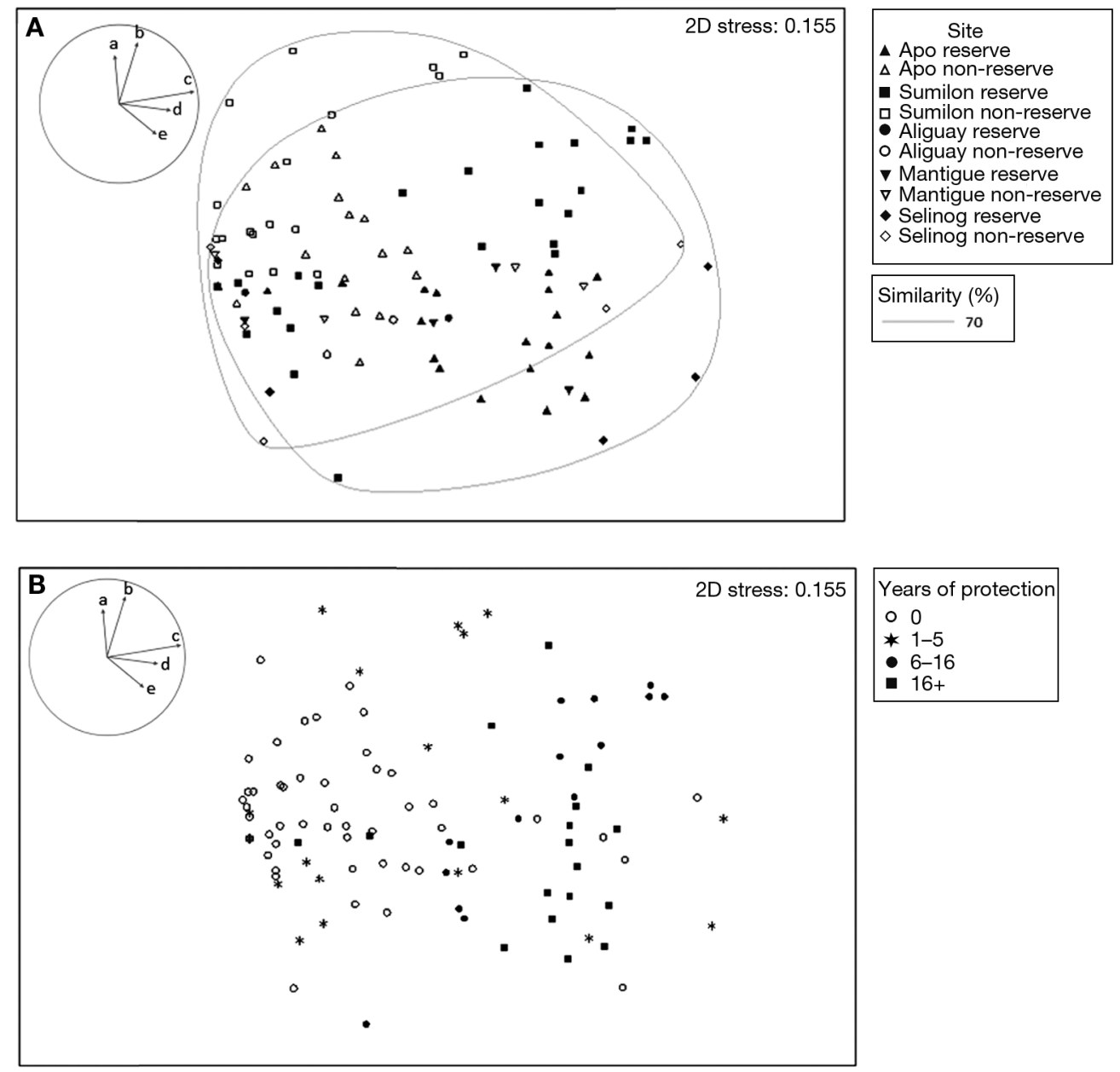

Fig. 7. Non-metric multi-dimensional scaling (MDS) of 5 species each of targeted lethrinids and lutjanids at 5 paired no-take marine reserves (NTMRs) and control sites over time (see Table 1 for years surveyed at each site) in the central Philippines, labelled by (A) site and (B) number of years of NTMR protection. Ellipses in (A) represent $70 \%$ similarity from cluster analysis (based on Bray-Curtis similarity matrix). Insets indicate vectors of species with a correlation $>60 \%$. a: Lethrinus obsoletus; b: L. harak; c: Lutjanus monostigma; d: Lethrinus erythracanthus; e: Monotaxis grandoculis

The assemblage structure of the targeted lethrinid/ lutjanids had weak spatial differentiation among islands, but showed stronger differentiation based on duration of NTMR protection (Fig. 7, Fig. S2 in the Supplement). There was no clear relationship between lethrinid/lutjanid assemblage structure (Fig. 7A) and benthos (Fig. 5). Two species (Lethrinus obsoletus and L. harak) were more common in areas with high cover of DS and low SCI, while 3 other species (Lutjanus monostigma, Lethrinus erythracanthus, and Monotaxis grandoculis) were more common on structurally complex reef slopes with high cover of HC (Fig. 7A). If targeted fishes responded to NTMR effects, this could be detected by assemblages in reserve and control sites being more clearly separated in multivariate space when labelled by duration of reserve protection (Fig. 7B) rather than by site location (Fig. 7A). The lethrinid/ lutjanid assemblages at sites with either little $(\leq 5 \mathrm{yr})$ or no NTMR protection separated in multivariate space from those assemblages with longer $(6-16+y r)$ NTMR protection (Fig. 7B). However, note that sites with $>10$ yr NTMR protection occurred exclusively at Sumilon and Apo reserves. Also note that the Apo reserve 2012 and 2013 assemblages (2 black squares, 16+ yr of protection, far left Fig. 7B) are more closely related in multivariate space to sites with little or no protection, following massive typhoon damage to the benthos and low targeted fish density. Pomacentrid species showed greater correlations within the MDS than did lethrinid/ lutjanid species (Figs. $6 \& 7$ ). 
Table 4. Variance explained (\%) of fish assemblage structure by the BEST BIO-ENV routine for targeted species (lethrinids and lutjanids) and non-targeted species (pomacentrids). The top 10 models are shown for each fish group (top models in bold). In addition, the best model for targeted species that did not include years of no-take marine reserve protection and the best model for non-target species that did not include benthic habitat variables are shown and indicated by italic font. DS: dead substratum cover; HC: hard coral cover; SC: soft coral cover; SCI: structural complexity

\begin{tabular}{|lcc|}
\hline & $\begin{array}{c}\text { No. of } \\
\text { variables }\end{array}$ & $\begin{array}{c}\text { Var. } \\
\text { expl. }(\%)\end{array}$ \\
\hline Targeted species & & \\
Years protected & $\mathbf{1}$ & $\mathbf{3 6 . 2}\left(\mathbf{4 2 . 2 ^ { \mathrm { a } } )}\right.$ \\
Years protected + DS & 2 & 32.2 \\
Years protected + SCI + DS & 3 & 31.5 \\
Years protected + HC + SCI + DS & 4 & 30.4 \\
Years protected + HC + SCI & 3 & 30.3 \\
Years protected + HC & 2 & 30.1 \\
Years protected + SCI & 2 & 29.7 \\
Years protected + HC + DS & 3 & 28.7 \\
Years protected + HC + Slope + & 5 & 27.5 \\
SCI + DS & & \\
Years protected + Slope + SCI + DS & 4 & 27.4 \\
HC + SCI & 2 & 24.7 \\
Non-targeted species & & \\
SCI + DS & $\mathbf{2}$ & $\mathbf{6 5 . 8}$ \\
HC + SCI + DS & 3 & 60.7 \\
HC + SCI & 2 & 58.6 \\
SCI + DS + SC & 3 & 56.8 \\
SCI & 1 & 56.4 \\
HC + SCI + DS + SC & 4 & 55.5 \\
HC + SCI + SC & 3 & 54.9 \\
HC + Slope + SCI + DS & 4 & 53.1 \\
Slope + SCI + DS & 3 & 52.5 \\
Years protected + SCI + DS & 3 & 52.0 \\
Years protected & 1 & 9.7 \\
ayphoon effects on Apo reserve in $2012-2013$ & omitted \\
& & \\
\hline
\end{tabular}

The BEST BIO-ENV Routine (PRIMER) identified the benthic habitat or NTMR protection factor(s) that explained the greatest variance in assemblage structure of targeted and non-targeted fish (Table 4) (Clarke \& Warwick 2001). Benthic habitat factors most clearly differentiated the assemblage structure of non-targeted pomacentrids. Percent cover of dead substrate (i.e. not live hard or soft coral) and structural complexity combined explained $65.8 \%$ of the variance in the pomacentrid assemblage $($ Rho $=$ $0.658, \mathrm{p}=0.01$; Table 4 ). The best model that included only duration of NTMR protection explained just $9.7 \%$ of the structure of the non-target pomacentrid assemblage (Table 4). In contrast, the most important determinant of assemblage structure of targeted lethrinids/lutjanids was duration of NTMR protection, explaining $36.2 \%$ of the variance $(\mathrm{Rho}=$
0.362, $p=0.01$; Table 4). Re-analysis excluding the Apo reserve 2012 and 2013 outliers (i.e. omitting the assemblages of targeted fish affected by the typhoons) strengthened the variance explained to $42.2 \%$. The addition of benthic habitat variables did not improve the model fit for the targeted fish group. The best model that included only benthic habitat variables explained just $24.7 \%$ of the structure of the lethrinid/lutjanid assemblage (Table 4).

\section{DISCUSSION}

Target fish densities were predicted to increase in NTMRs relative to controls over time, with a significant time $\times$ NTMR status interaction. This pattern was detected at all 4 islands, with 4 - to 75 -fold higher density in NTMRs relative to fished areas over durations of 9-29 yr. The initial increase in density was more rapid at Matingue and Selinog reserves than at Apo or Sumilon reserves. Substantial increases in density and biomass of predatory fishes due to longterm protection have been recorded in Apo and Sumilon NTMRs (Russ \& Alcala 2003, 2010, 2011) and in Kenyan NTMRs (McClanahan \& Arthur 2001, McClanahan et al. 2007, McClanahan 2014). McClanahan \& Arthur (2001) similarly found that protection from fishing had stronger effects on targeted reef fish density than habitat characteristics.

Density of non-targeted reef fishes did not display any clear NTMR effects. Non-targeted fishes showed no significant time $\times$ NTMR status interaction except at Selinog, and pomacentrid densities increased only at Selinog and Mantigue reserves. However, baseline ('before') data for Selinog and Mantigue Islands were collected in 1999, following the 1998 severe coral bleaching event (Arceo et al. 2001), and reduction in coral cover was also observed at Apo and Sumilon. Thus, by chance, monitoring began when live coral cover had likely been reduced. This probable coral reduction may explain the rise in coral cover and consequently increased pomacentrid densities over time at Selinog and Mantigue NTMRs. Few studies have examined NTMR effects on pomacentrids since these species are generally not targeted by fishing. Notable exceptions include studies on Kenyan (McClanahan 1994, McClanahan et al. 1999, McClanahan et al. 2007), Philippine (Russ \& Alcala 1998a,b), and Australian (Graham et al. 2003) coral reefs. However, Russ \& Alcala (1998b) reported no strong NTMR effects on pomacentrid density in over a decade at Sumilon and Apo NTMRs in the Philippines. McClanahan et al. (2007) also found no signif- 
icant effect of long-term NTMR protection on pomacentrid density on Kenyan coral reefs, although they did report a significant linear increase in species richness of pomacentids with NTMR protection. Graham et al. (2003) reported an indirect NTMR effect on pomacentrids (discussed below). While all islands had a significant time $\times$ NTMR status interaction for hard coral cover, none of the temporal trends were consistent with a reserve effect (increased coral cover in NTMRs relative to fished controls). The significant time $\times$ NTMR status interactions were likely driven by variations in coral cover caused by environmental disturbances or statistical artifacts. Only Mantigue showed a trajectory that appeared consistent with a direct, positive NTMR effect on coral cover. However, live coral cover at Mantigue nonreserve declined due to a COTS outbreak in 2003, an effect still evident in 2007. Mantigue reserve was not affected by this COTS outbreak and coral cover increased slightly. In a global review, Selig \& Bruno (2010) reported modestly higher maintenance of coral cover in marine protected areas than fished areas. Furthermore, NTMRs in the Caribbean can enhance coral recruitment (Harborne et al. 2008). However, these conclusions are not consistent with results from the 2 longest running studies of NTMR effects on coral cover, the present study and that of McClanahan (2014). McClanahan (2014) reported no significant change in coral cover with up to $40 \mathrm{yr}$ of NTMR protection on Kenyan coral reefs, although an Indian-Ocean-wide analysis suggested that very low fishable biomass was associated with reduced cover of hard corals (McClanahan et al. 2011).

The influence of potential prey (non-targeted species) density on targeted species density was larger than the influence of potential predators (targeted species) on non-targeted species. Furthermore, the removal of potential predators through fishing or increases/recovery of potential predators due to NTMR protection had the lowest influence on pomacentrid density compared to the influence of changes in benthic habitat. This suggests that bottom-up forces may be playing a stronger role than top-down forces on these species on Philippine coral reefs. This interpretation is supported by observations of higher densities of predators in places with higher densities of potential prey (Hobson 1991). Our result contrasts with those of Graham et al. (2003), who showed that reductions in biomass of a large piscivorous coral reef grouper resulted in density increases of known prey fishes. Graham et al. (2003) had the benefit of location- and species-specific dietary data for the single predator. Hence, without location- and species- specific dietary information, there is a degree of uncertainty in our estimates of the relative influence of trophic interactions between targeted and nontargeted species.

Environmental disturbance events differed in severity and effect on corals. Many fishes appear to have greater resistance to effects of coral bleaching or coral disease, which leave coral skeletons intact, compared to the reductions of physical reef structure that often occur after typhoons (Graham et al. 2006, Wilson et al. 2006, Coker et al. 2014). The severity of disturbance can also influence recovery rates of corals and benthic habitat (Wilson et al. 2006, Baker et al. 2008). Corals tended to recover following disturbances such as coral bleaching and COTS outbreaks (e.g. at Sumilon and Apo reserves), but effects of typhoons on coral cover were more substantial, and thus required longer recovery times. These large benthic changes also had greater impacts on both groups of fishes than other types of environmental disturbance. Coral recovery rates were variable in time and space, consistent with other studies (Baker et al. 2008, Smith et al. 2008).

Lethrinids/lutjanids were less affected by benthic habitat changes than were pomacentrids. Long-term upward trends in both percent cover of hard corals and density of targeted fish were observed at Apo non-reserve and Selinog and Mantigue reserves. Conversely, the effects of 2 typhoons at Apo reserve (2012 and 2013) demonstrated that if hard coral cover and structural complexity of the substrate is reduced dramatically, targeted fish density can also be reduced. This suggests a required threshold level of benthic habitat quality or available prey species. Pratchett et al. (2011) posited similar conclusions in a review of habitat disturbances on coral reefs. Specifically they found that declines of coral cover greater than $60 \%$ led to substantial reductions of reef fish diversity. Reserve status may provide little protection for targeted fishes following large reductions in the quality of benthic habitat (Jones et al. 2004, Graham et al. 2006). However, lethrinids/lutjanids may be more resilient to benthic habitat change due to weaker associations with the benthos than the pomacentrids, increased mobility, and/or the greater relative importance of fishing pressure (see also Graham et al. 2006, McClanahan et al. 2007).

Both spatial and temporal differences in NTMR protection and benthic habitat affected fish assemblage structure, but with differing relative influences on targeted and non-targeted fish densities. Pinca et al. (2012) found that $20 \%$ of variance in reef fish density could be explained by fishing pressure, and 30\% 
by habitat variability. In St. Lucia, West Indies, Hawkins et al. (2006) found that reserve status explained $44 \%$ of the variance in reef fish density, but coral cover and structural complexity were nonsignificant. The present study found that $65.8 \%$ of the variability in assemblage structure of non-targeted pomacentrids was explained by benthic habitat, but only $9.7 \%$ could be explained by duration of NTMR protection alone. Conversely, NTMR protection explained $36.2 \%$ of the variation in the assemblage structure of targeted lethrinids/lutjanids and habitat alone explained only $24.7 \%$. The influence of NTMR protection on assemblage structure of target fish was greater $(42.2 \%)$ if the effects of the typhoons at Apo Island in 2012 and 2013 were ignored. This wide range of results suggests that the relative effects of benthic habitat and NTMR status may be species specific, site specific, or related to fishing pressure outside the reserve.

Examining changes in total fish density masked individual species-level changes and associations with particular habitat variables. For example, 6 pomacentrid species were associated with sites with high hard coral cover and structural complexity, and these species are typically found to be coral associated (Pratchett et al. 2012, Coker et al. 2014). In contrast, Dascyllus reticulatus, D. trimaculatus, and Plectroglyphidodon lacrymatus were associated with sites with high dead substrate and low structural complexity, but the Dascyllus spp. frequently associate with live corals within sandy areas (Russ \& Alcala 1998a, Pratchett et al. 2012, Coker et al. 2014)

Comparisons of NTMRs and fished sites in this study were heavily confounded by benthic habitat. Most reserves were placed by local communities on steep reef slopes with high coral cover for attracting dive tourism. Due to the small size and geomorphology of these islands, it was difficult to find similar benthic habitats in control (fished) areas. Thus, differentiation of the effects of benthic habitat and NTMR protection on fish assemblage structure must be interpreted with caution, even with robust BACIP study designs and long-term monitoring. Many other factors also influence benthic habitat and fish assemblage structure, such as environmental conditions (Hawkins et al. 2006), larval supply (Russ 2002), fishing pressure and fishing methods (McClanahan et al. 2011, Edgar et al. 2014), and site history and enforcement of NTMR protection (Alcala \& Russ 2006, Edgar et al. 2014).

These results underscore the long-term role of NTMRs in enhancing targeted fish densities in the Philippines. Targeted lethrinids/lutjanids were most strongly influenced by NTMR protection status, whereas non-targeted pomacentrids were more strongly influenced by benthic habitat factors. Habitat differences among NTMR and fished control sites may make the detection of NTMR effects difficult, and any such differences must be included in study designs and/or statistically accounted for to properly evaluate the benefits of NTMR protection. While trophic effects were relatively weak in this study, bottom-up processes appeared to be stronger than top-down effects. This study demonstrates that benefits of NTMRs for targeted species are not solely due to inherent site differences, as shown by BACIP sampling designs applied on long (8-30 yr) time scales.

Acknowledgements. This research was supported by the Australian Research Council Centre for Coral Reef Studies and the College of Marine and Environmental Sciences at James Cook University, and a Pew Fellowship to G.R.R. and A.C.A. (1999-2002). Thanks to S. Leahy, E. Miller, and three anonymous reviewers for very helpful comments on the manuscript.

\section{LITERATURE CITED}

Alcala AC, Russ GR (2006) No-take marine reserves and reef fisheries management in the Philippines: a new people power revolution. Ambio 35:245-254

Allison GW, Lubchenco J, Carr MH (1998) Marine reserves are necessary but not sufficient for marine conservation. Ecol Appl 8:S79-S92

Arceo HO, Quibilan MC, Alino PM, Lim G, Licuanan WY (2001) Coral bleaching in Philippine reefs: coincident evidences with mesoscale thermal anomalies. Bull Mar Sci 69:579-593

Babcock RC, Shears NT, Alcala AC, Barrett NS and others (2010) Decadal trends in marine reserves reveal differential rates of change in direct and indirect effects. Proc Natl Acad Sci USA 107:18256-18261

Baker AC, Glynn PW, Riegl B (2008) Climate change and coral reef bleaching: an ecological assessment of longterm impacts, recovery trends and future outlook. Estuar Coast Shelf Sci 80:435-471

> Bellwood DR, Hughes TP (2001) Regional-scale assembly rules and biodiversity of coral reefs. Science 292: 1532-1535

Burnham KP, Anderson DR (2002) Model selection and multimodel inference: a practical information-theoretic approach. Springer, New York, NY

Burnham KP, Anderson DR (2004) Multimodel inference: understanding AIC and BIC in model selection. Sociol Methods Res 33:261-304

Chapman MR, Kramer DL (1999) Gradients in coral reef fish density and size across the Barbados Marine Reserve boundary: effects of reserve protection and habitat characteristics. Mar Ecol Prog Ser 181:81-96

Clarke KR, Warwick RM (2001) Changes in marine communities: an approach to statistical analysis and interpretation. PRIMER-E, Plymouth

Claudet J, Guidetti P (2010) Improving assessments of marine protected areas. Aquat Conserv 20:239-242 
Coker DJ, Wilson SK, Pratchett MS (2014) Importance of live coral habitat for reef fishes. Rev Fish Biol Fish 24:89-126

$>$ De'ath G (2007) Boosted trees for ecological modeling and prediction. Ecology 88:243-251

> Edgar GJ, Barrett NS (1997) Short term monitoring of biotic change in Tasmanian marine reserves. J Exp Mar Biol Ecol 213:261-279

- Edgar GJ, Bustamante RH, Farina JM, Calvopina M, Martinez C, Toral-Granda MV (2004) Bias in evaluating the effects of marine protected areas: the importance of baseline data for the Galapagos Marine Reserve. Environ Conserv 31:212-218

> Edgar GJ, Barrett NS, Stuart-Smith RD (2009) Exploited reefs protected from fishing transform over decades into conservation features otherwise absent from seascapes. Ecol Appl 19:1967-1974

Edgar GJ, Stuart-Smith RD, Willis TJ, Kininmonth S and others (2014) Global conservation outcomes depend on marine protected areas with five key features. Nature 506: 216-220

Elith J, Leathwick JR, Hastie T (2008) A working guide to boosted regression trees. J Anim Ecol 77:802-813

> Fabricius K, De'Ath G (2008) Photosynthetic symbionts and energy supply determine octocoral biodiversity in coral reefs. Ecology 89:3163-3173

García-Charton JA, Pérez-Ruzafa Á (1999) Ecological heterogeneity and the evaluation of the effects of marine reserves. Fish Res 42:1-20

García-Charton JA, Pérez-Ruzafa Á, Sánchez-Jerez P, Bayle-Sempere JT, Reñones O, Moreno D (2004) Multiscale spatial heterogeneity, habitat structure, and the effect of marine reserves on Western Mediterranean rocky reef fish assemblages. Mar Biol 144:161-182

Graham NAJ, Evans RD, Russ GR (2003) The effects of marine reserve protection on the trophic relationships of reef fishes on the Great Barrier Reef. Environ Conserv 30: 200-208

Graham NAJ, Wilson SK, Jennings S, Polunin NVC, Bijoux JP, Robinson J (2006) Dynamic fragility of oceanic coral reef ecosystems. Proc Natl Acad Sci USA 103:8425-8429

Graham NAJ, Ainsworth TD, Baird AH, Ban NC and others (2011) From microbes to people: tractable benefits of notake areas for coral reefs. Oceanogr Mar Biol Annu Rev 49:117-148

Guidetti P, Milazzo M, Bussotti S, Molinari A and others (2008) Italian marine reserve effectiveness: does enforcement matter? Biol Conserv 141:699-709

> Halpern BS (2003) The impact of marine reserves: Do reserves work and does reserve size matter? Ecol Appl 13:117-137

> Harborne AR, Mumby PJ, Kappel CV, Dahlgren CP and others (2008) Reserve effects and natural variation in coral reef communities. J Appl Ecol 45:1010-1018

- Harmelin-Vivien M, Le Diréach L, Bayle-Sempere J, Charbonnel E and others (2008) Gradients of abundance and biomass across reserve boundaries in six Mediterranean marine protected areas: evidence of fish spillover? Biol Conserv 141:1829-1839

- Hawkins JP, Roberts CM, Dytham C, Schelten C, Nugues MM (2006) Effects of habitat characteristics and sedimentation on performance of marine reserves in St. Lucia. Biol Conserv 127:487-499

Heupel MR, Knip DM, Simpfendorfer CA, Dulvy NK (2014) Sizing up the ecological role of sharks as predators. Mar Ecol Prog Ser 495:291-298
Hobson ES (1991) Trophic relationships of fishes specialized to feed on zooplankters above coral reefs. In: Sale PF (ed) The ecology of fishes on coral reefs. Academic Press, San Diego, CA, p 69-95

> Humphries AT, McClanahan TR, McQuaid CD (2014) Differential impacts of coral reef herbivores on algal succession in Kenya. Mar Ecol Prog Ser 504:119-132

Jackson JBC, Kirby MX, Berger WH, Bjorndal KA and others (2001) Historical overfishing and the recent collapse of coastal ecosystems. Science 293:629-637

Jones GP, Cole RC, Battershill CN (1992) Marine reserves: do they work. In: Battershill C, Schiel D, Jones G, Creese R, MacDiarmid A (eds) 2nd Int Temperate Reef Symp. National Institute of Water and Atmospheric Research, Wellington, p 29-45

Jones GP, McCormick MI, Srinivasan M, Eagle JV (2004) Coral decline threatens fish biodiversity in marine reserves. Proc Natl Acad Sci USA 101:8251-8253

Kellner JB, Litvin SY, Hastings A, Micheli F, Mumby PJ (2010) Disentangling trophic interactions inside a Caribbean marine reserve. Ecol Appl 20:1979-1992

- Kulbicki M, Bozec YM, Labrosse P, Letourneur Y, MouTham G, Wantiez L (2005) Diet composition of carnivorous fishes from coral reef lagoons of New Caledonia. Aquat Living Resour 18:231-250

Lester SE, Halpern BS, Grorud-Colvert K, Lubchenco J and others (2009) Biological effects within no-take marine reserves: a global synthesis. Mar Ecol Prog Ser 384:33-46

Lubchenco J, Palumbi SR, Gaines SD, Andelman S (2003) Plugging a hole in the ocean: the emerging science of marine reserves. Ecol Appl 13:3-7

McClanahan TR (1994) Kenyan coral reef lagoon fish: effects of fishing, substrate complexity, and sea urchins. Coral Reefs 13:231-241

McClanahan TR (2014) Recovery of functional groups and trophic relationships in tropical fisheries closures. Mar Ecol Prog Ser 497:13-23

- McClanahan TR, Arthur R (2001) The effect of marine reserves and habitat on populations of East African coral reef fishes. Ecol Appl 11:559-569

- McClanahan TR, Muthiga NA, Kamukuru AT, Machano H, Kiambo RW (1999) The effects of marine parks and fishing on coral reefs of northern Tanzania. Biol Conserv 89: 161-182

McClanahan TR, Graham NA, Calnan JM, MacNeil MA (2007) Toward pristine biomass: reef fish recovery in coral reef marine protected areas in Kenya. Ecol Appl 17: 1055-1067

McClanahan TR, Graham NA, MacNeil MA, Muthiga NA, Cinner JE, Bruggemann JH, Wilson SK (2011) Critical thresholds and tangible targets for ecosystem-based management of coral reef fisheries. Proc Natl Acad Sci USA 108:17230-17233

Miller KI, Russ GR (2014) Studies of no-take marine reserves: methods for differentiating reserve and habitat effects. Ocean Coast Manage 96:51-60

Miller SL, Shima JS, Phillips NE (2012) Effects of microhabitat availability on estimates of density of a reef fish: implications for assessments of marine protected areas. Hydrobiologia 685:173-190

> Mumby PJ, Dahlgren CP, Harborne AR, Kappel CV and others (2006) Fishing, trophic cascades, and the process of grazing on coral reefs. Science 311:98-101

Myers RA, Worm B (2003) Rapid worldwide depletion of predatory fish communities. Nature 423:280-283 
Osenberg CW, Bolker BM, White J, Mary CMS, Shima JS (2006) Statistical issues and study design in ecological restorations: lessons learned from marine reserves. In: Falk D, Palmer M, Zedler J (eds) Foundations of restoration ecology. Island Press, Washington, DC, p 280-302

Osenberg CW, Shima JS, Miller SL, Stier AC (2011) Assessing effects of marine protected areas: confounding in space and possible solutions. In: Claudet J (ed) Marine protected areas: a multidisciplinary approach. Ecology, biodiversity and conservation. Cambridge University Press, Cambridge, p 143-167

Pikitch EK, Santora C, Babcock EA, Bakun A and others (2012) Ecosystem-based fishery management. Science 305:346-347

Pinca S, Kronen M, Magron F, McArdle B, Vigliola L, Kulbicki M, Andréfouët S (2012) Relative importance of habitat and fishing in influencing reef fish communities across seventeen Pacific Island countries and territories. Fish Fish 13:361-379

> Pratchett MS, Hoey AS, Wilson SK, Messmer V, Graham NAJ (2011) Changes in biodiversity and functioning of reef fish assemblages following coral bleaching and coral loss. Diversity 3:424-452

Pratchett MS, Coker DJ, Jones GP, Munday PL (2012) Specialization in habitat use by coral reef damselfishes and their susceptibility to habitat loss. Ecol Evol 2:2168-2180

R Core Team (2012) R: a language and environment for statistical computing. R Foundation for Statistical Computing, Vienna, Austria

Ridgeway G (2006) Generalized boosted regression models. Documentation on the $\mathrm{R}$ package 'gbm', version 1.5-7. http://ftp.auckland.ac.nz/software/CRAN/doc/packages/ gbm.pdf

Rizzari JR, Frisch AJ, Hoey AS, McCormick MI (2014) Not worth the risk: apex predators suppress herbivory on coral reefs. Oikos 123:829-836

Roberts CM (2000) Selecting marine reserve locations: optimality versus opportunism. Bull Mar Sci 66:581-592

Roberts CM, Branch G, Bustamante RH, Castilla JC and others (2003) Application of ecological criteria in selecting marine reserves and developing reserve networks. Ecol Appl 13:215-228

Ruppert JL, Travers MJ, Smith LL, Fortin MJ, Meekan MG (2013) Caught in the middle: combined impacts of shark removal and coral loss on the fish communities of coral reefs. PLoS ONE 8:e74648

Russ GR (2002) Yet another review of marine reserves as reef fishery management tools. In: Sale PF (ed) Coral reef fishes: dynamics and diversity in a complex ecosystem. Academic Press, New York, NY, p 421-444

Russ GR, Alcala AC (1998a) Natural fishing experiments in marine reserves 1983-1993: community and trophic responses. Coral Reefs 17:383-397

Editorial responsibility: Tim McClanahan, Mombasa, Kenya
Russ GR, Alcala AC (1998b) Natural fishing experiments in marine reserves 1983-1993: roles of life history and fishing intensity in family responses. Coral Reefs 17:399-416

Russ GR, Alcala AC (2003) Marine reserves: rates and patterns of recovery and decline of predatory fish, 19832000. Ecol Appl 13:1553-1565

> Russ GR, Alcala AC (2010) Decadal-scale rebuilding of predator biomass in Philippine marine reserves. Oecologia 163:1103-1106

> Russ GR, Alcala AC (2011) Enhanced biodiversity beyond marine reserve boundaries: The cup spillith over. Ecol Appl 21:241-250

Russ GR, Stockwell B, Alcala AC (2005) Inferring versus measuring rates of recovery in no-take marine reserves. Mar Ecol Prog Ser 292:1-12

Sale PF, Cowen RK, Danilowicz BS, Jones GP and others (2005) Critical science gaps impede use of no-take fishery reserves. Trends Ecol Evol 20:74-80

Selig ER, Bruno JF (2010) A global analysis of the effectiveness of marine protected areas in preventing coral loss. PLoS ONE 5:e9278

Shears NT, Grace RV, Usmar NR, Kerr V, Babcock RC (2006) Long-term trends in lobster populations in a partially protected vs. no-take marine park. Biol Conserv 132: $222-231$

Smith LD, Gilmour JP, Heyward AJ (2008) Resilience of coral communities on an isolated system of reefs following catastrophic mass-bleaching. Coral Reefs 27: 197-205

Smith JE, Hunter CL, Smith CM (2010) The effects of top-down versus bottom-up control on benthic coral reef community structure. Oecologia 163:497-507

Sutcliffe P, Mellin C, Pitcher C, Possingham H, Caley M (2014) Regional-scale patterns and predictors of species richness and abundance across twelve major tropical inter-reef taxa. Ecography 37:162-171

Thresher RE (1983) Habitat effects on reproductive success in the coral reef fish, Acanthochromis polyacanthus (Pomacentridae). Ecology 64:1184-1199

> Wilson SK, Graham NAJ, Pratchett MS, Jones GP, Polunin NVC (2006) Multiple disturbances and the global degradation of coral reefs: are reef fishes at risk or resilient? Glob Change Biol 12:2220-2234

Wilson S, Fisher R, Pratchett M, Graham N and others (2008) Exploitation and habitat degradation as agents of change within coral reef fish communities. Glob Change Biol 14: 2796-2809

Wilson SK, Fisher R, Pratchett MS, Graham NAJ and others (2010) Habitat degradation and fishing effects on the size structure of coral reef fish communities. Ecol Appl 20: $442-451$

Wood S (2006) Generalized additive models: an introduction with R. CRC Press, Boca Raton, FL

Submitted: August 22, 2014; Accepted: February 18, 2015 Proofs received from author(s): May 7, 2015 